2 Production of domoic acid by laboratory culture of the red alga Chondria armata

4

5 Shanshan Jiang ${ }^{\mathrm{a}}$, Kazuyoshi Kuwano ${ }^{\mathrm{a}}$, Nozomi Ishikawa $^{\mathrm{b}}$, Michiko Yano ${ }^{\mathrm{b}}$, Tomohiro

6 Takatani $^{\mathrm{a}}$, Osamu Arakawa ${ }^{\mathrm{a}, *}$

7

$8{ }^{a}$ Graduate School of Fisheries Science and Environmental Studies, Nagasaki University, 1-14,

9 Bunkyo-machi, Nagasaki 852-8521, Japan

$10 \quad{ }^{b}$ Faculty of Fisheries, Nagasaki University, 1-14, Bunkyo-machi, Nagasaki 852-8521, Japan

*Corresponding author. Tel/fax: +81 958192844.

15

E-mail address: arakawa@nagasaki-u.ac.jp (O. Arakawa)

\title{
19 Highlights
}

20 > The red alga C. armata was cultured

21 > Excessive manganese inhibited C. armata growth

22 > Domoic acid content of cultured explants was 4-5 fold that of wild specimens

$23>$ C. armata produced domoic acid 

3

\section{Abstract}

To clarify the production mechanisms and biologic functions of domoic acid (DA) by the red alga Chondria armata, we established a laboratory culture of C. armata. The alga grew better in modified PES medium (mPES) without trace metals or manganese than in unmodified mPES (seawater + nitrate, phosphate, iron, trace metals, vitamins, and 2-[4-(2-hydroxyethyl)-1-piperazinyl]-ethanesulfonic acid), suggesting that C. armata is especially hypersensitive to the toxicity of excessive manganese. C. armata cultured in $\mathrm{N} \cdot \mathrm{P} \cdot \mathrm{Fe}$ medium (seawater + nitrate, phosphate, and iron) grew best (mean growth rate 828.4\%) at a relative nutrient concentration of 50\%. Liquid chromatography-mass spectrometry analysis of the algal extracts revealed that the DA content of the cultured explants (2273-3308 ppm) was 4 to 5 fold higher than that of wild specimens. The extract of pooled explants (60 g) was purified by activated charcoal treatment and several types of column chromatography to afford ca. $10 \mathrm{mg}$ DA. The ${ }^{1} \mathrm{H}$-nuclear magnetic resonance spectrum of the preparation was indistinguishable from the previously reported spectrum of DA, indicating that C. armata itself has an ability to produce DA.

Keywords: Domoic acid (DA); amnesic shellfish poisoning (ASP); red alga; Chondria armata; laboratory culture; modified PES medium 


\section{Introduction}

In November 1987, mass food poisoning occurred in Eastern Canada following the ingestion of the mussel Mytilus edulis. In addition to general signs, such as abdominal pain, diarrhea, and vomiting, the victims exhibited unique nervous system symptoms including memory loss, and the poisoning was thus called amnesic shellfish poisoning (Teitelbaum et al., 1990). Subsequent studies revealed that domoic acid (DA) was the causative substance of the human intoxication, and that the mussels became toxic by ingesting and accumulating DA originally produced by the diatom Pseudo-nitzschia pungens forma multiseries (Bates et al., 1989; Wright et al., 1989). DA is an excitatory amino acid primarily isolated as an anthelminthic principal from the red alga Chondria armata (Daigo, 1959), which inhabitants of an isolated island in the Kagoshima Prefecture used to take to expel their intestinal worms. DA has extremely high affinity for glutamate receptors in the central nervous system (Zaczek and Coyle, 1982; Debonnel et al., 1989), and a heavy overdose of DA causes dysmnesia by destroying the CA3 region of the hippocampus, which coordinates memory in the cerebrum (Strain and Tasker, 1991). After the occurrence of amnesic shellfish poisoning, several studies were conducted to examine the distribution, growth characteristics, and DA productivity of diatoms, the transfer/accumulation of DA via the food chain to other marine organisms, abnormal behavior and death of animals following DA ingestion, and the mechanism of human intoxication (Perl et al., 1990; Kotaki et al., 1999). The biosynthetic pathway of DA has been studied in diatoms (Ramsey et al., 1998; Thomas et al., 2012). C. armata, however, is quite difficult to culture, and, although there are some reports of DA in wild algal specimens and coexisting DA isomers (Noguchi and Arakawa, 1996; Zaman et al., 1997), little information is available on the production mechanisms and physiologic functions of DA 
in the alga. To elucidate this point, we established a laboratory culture of $C$. armata.

\section{Materials and methods}

\subsection{Culture materials}

Thalli of C. armata were collected at Hanasezaki, Kagoshima Prefecture, Japan, in August 2007. They were immediately placed in a bottle containing natural seawater and brought back alive to the laboratory of Nagasaki University. The thalli were preserved in autoclaved seawater at $21^{\circ} \mathrm{C}$ under photosynthetically active radiation of $80 \mu \mathrm{mol}$ photons $\cdot \mathrm{m}^{-2} \cdot \mathrm{s}^{-1}$ provided by cool-white fluorescent lamps with a photoperiod of 14:10 light:dark. The branches of the thalli were rinsed several times with the autoclaved seawater, and 50- to $100-\mu \mathrm{m}$ long apexes were cut with a needle sharpened into a microscopic blade under a stereoscopic microscope (SZ60; Olympus). These apex explants were used for the following experiments.

\subsection{Investigation of culture medium}

Modified PES medium (mPES; seawater + nitrate, phosphate, iron, trace metals, vitamins, and 2-[4-(2-hydroxyethyl)-1-piperazinyl]-ethanesulfonic acid) (Provasoli, 1968; Kuwano et al., 1998) prepared with filter-sterilized or autoclaved seawater was used as the primary medium in the present study (Table 1). Various media were prepared by removing components from the primary medium to determine the suitable composition of nutrients for the growth of C. armata [experiment (Exp) 1]. In the experiment, an apex was placed in each well of a 24-well plate filled with the prepared media (3-4 wells used for each medium), and 
incubated under the conditions described above. Growth was evaluated based on the development of a trichome (Fig. 1, upper panel) and the color of the apex explants. DA production by the cultured thalli was examined in Exp 2. Apex explants grown without other algae, fungi, or protozoa in wells of the 24-well plate were carefully selected under an inverted microscope (CKX41; Olympus), and cultured for 30 days in 1-L flat-bottom flasks containing various media under the conditions described above. Three pieces of the branches were placed in each flask and filter-sterilized air was continuously provided through an inlet at the bottom corner of the flask. The growth rate was calculated as the percentage of the fresh weight of the thalli at the end of the culture to that at the beginning of the culture, and the DA content was determined by the following method.

\subsection{Determination of DA content}

The explants obtained in Exp 2 (3 explants cultured with each medium were combined), and wild algae (3 lots) were extracted with water. Each extract was passed through an HLC-DISK membrane filter (0.45 $\mu \mathrm{m}$; Kanto Chemical Co., Inc.), and subjected to liquid chromatography-mass spectrometry (LC-MS) (Japan Food Hygiene Association, 2005). Analysis was performed using an Alliance LC-MS system (Waters) equipped with a ZsprayTM MS 2690 detector. A Mightysil RP-18 GP column (250 x 2.0 mm; Kanto Chemical Co., Inc.) was used with $1 \%$ acetic acid in $12 \%$ aqueous acetonitrile as the mobile phase. The flow rate was set to $0.2 \mathrm{ml} / \mathrm{min}$, and the column temperature at $35^{\circ} \mathrm{C}$. DA was ionized by a positive mode of electrospray ionization (ESI) with a desolvation temperature of $350^{\circ} \mathrm{C}$, source block temperature at $120^{\circ} \mathrm{C}$, and cone voltage of $30 \mathrm{~V}$, and then monitored through a MassLynxTM NT operating system. 


\subsection{Nuclear magnetic resonance spectral analysis}

From the explants $(60 \mathrm{~g})$ cultured in 1-L flat-bottom flasks with $\mathrm{N} \cdot \mathrm{P} \cdot \mathrm{Fe}$ medium (seawater + nitrate, phosphate, and iron; Table 1) for 87 to 157 days (Fig. 1, lower panel), putative DA (CaDA) was extracted with water, and purified by activated charcoal treatment, followed by several types of chromatography using a Bio-Gel P-2 column $(3 \times 30 \mathrm{~cm}$; Bio-Rad Laboratories) with 0.03 M acetic acid, a P-P-C column (Nihon Seimitsu), and an ODS column

( $2 \times 25 \mathrm{~cm}$; Waters) with $1 \%$ acetic acid in $5 \%$ or $4 \%$ aqueous acetonitrile as the mobile phase

\section{Results}

In Exp 1, the apex explants developed few or no trichomes and remained small in size in unmodified mPES. They appeared, however, vigorous and had well-developed trichomes when trace metals or manganese were removed from the medium (Fig. 1, upper panel), suggesting that manganese was harmful to C. armata. The removal of HEPES and the vitamin mix did not affect the results, but as further attempts to remove iron, nitrate, and phosphate were ineffective, some or all of these components were suggested to be necessary for $C$. armata growth. Based on the above results, medium with added nitrate, phosphate, and iron to seawater (N·P·Fe; Table 1 ) was used to investigate DA production by $C$. armata culture in Exp 2. Growth varied according to the concentration of the nutrient mix, and the maximum growth rate was $828.4 \%$ at half the original concentration (Fig. 2). Explants from each 
medium were pooled, extracted with water, and then submitted to LC-MS analysis, in which all of the extracts produced a peak whose retention time was identical to that of the DA standard in a selected ion chromatogram at m/z 312 (Fig. 3). The DA content calculated from the peak area was 2273-3308 ppm, 4- to 5-fold that in wild specimens (mean 587.5 ppm) (Fig. $4)$.

The putative DA ( $\mathrm{CaDA}$ ) extracted from the pooled explants (60 g) was purified by activated charcoal treatment and several types of column chromatography to afford ca. $10 \mathrm{mg}$ of a single component. The ${ }^{1} \mathrm{H}-\mathrm{NMR}$ data of the purified $\mathrm{CaDA}$ are provided in Table 2. Both chemical shifts and signal configurations were identical with those of previously reported DA (Wright et al., 1990).

\section{Discussion}

The results of the present study demonstrated that C. armata could grow in the laboratory. The composition of the growth medium was key to promoting the growth. Although Provasoli's ES medium (Provasoli, 1968), the original mPES medium, is one of the most common media used for culturing algae in the laboratory, the concentration of manganese $(3.6 \mu \mathrm{M})$ had detrimental effects on $C$. armata growth. Manganese is required for a number of essential processes in plants, including oxygen evolution in photosynthesis and detoxification of oxygen-free radicals (Fox and Guerinot, 1998), although damage to terrestrial plants by excess manganese has been reported (Mukhopadhyay and Sharma, 1991), and it is also added to other growth media, such as F medium (Guillard and Ryther 1962) and ASP $_{12}$ NTA (Provasoli 1963), at concentrations close to or above $3.6 \mu \mathrm{M}$. Therefore, the difficulty of culturing $C$. armata is primarily due to its specific sensitivity to manganese. The 
requirement of manganese for the growth of $C$. armata is likely to be low, and the original concentration of manganese in natural seawater is sufficient for the fundamental needs of $C$. armata.

The addition of iron to the growth medium was necessary to grow $C$. armata. Iron is an essential element for plants and required for photosynthesis and respiratory electron transport, nitrate reduction, chlorophyll synthesis, and detoxification of reactive oxygen species (Sunda and Huntsman, 1995). Iron deficiency easily occurs in the marine environment, especially the open ocean, however, because of its insolubility in oxygenated seawater (Martin et al., 1991). The addition of iron to a site in the Pacific Ocean resulted in the increased productivity of phytoplankton, which supports the notion of an iron limitation (Martin et al., 1994). The iron requirement of coastal phytoplankton species was found to be much higher than that of ocean phytoplankton species in culture experiments (Brand et al. 1983). As C. armata grows on rocky shores, its iron requirement level is likely to be similar to that of coastal phytoplankton species.

Although the mean growth rate was highest in the $1 / 2 \mathrm{~N} \cdot \mathrm{P} \cdot \mathrm{Fe}$ medium (Fig. 2), the effect of nitrate and phosphate concentrations on the growth of $C$. armata remains unknown because the growth rate of each explant varied considerably, even under the same conditions. Although the present study led to the development of a basic technique for the laboratory cultivation of $C$. armata, further studies are needed to improve the culture technique.

The DA content of all of the explants in the present study exceeded 2000 ppm, an amount much higher than that of the wild specimens and corresponding values (201-381 ppm) in the previous study (Noguchi and Arakawa, 1996). The DA content of the explants before beginning the culture was not evaluated, but the detection of DA in laboratory culture 
explants that more than doubled in weight at concentrations 4 to 5 times higher than that in the wild specimens, and the fact that the ${ }^{1} \mathrm{H}-\mathrm{NMR}$ spectra of the DA extracted, purified, and isolated from the cultured explants were indistinguishable from the previously reported spectrum of DA strongly suggest that C. armata itself has the ability to produce DA, although the involvement of symbiotic bacteria cannot be ruled out. There are some reports on the productivity or biosynthetic pathway of DA in diatoms, but this, to our knowledge, is the first study to culture C. armata and indicate its ability to produce DA.

Although some possibilities, including the discharge of residual energy in the cells and osmoregulation are physiologic and ecologic functions of DA in diatoms (Bates, 1998), no information is available on its physiologic and ecologic functions in C. armata. Further studies are in progress to elucidate this point, as well as the biosynthetic pathway of DA in $C$. armata.

\section{Acknowledgements}

We would like to express sincere thanks to Professor Yoshitaka Sakakura, Graduate School of Fisheries Science and Environmental Studies, Nagasaki University, for reading the manuscript. This study was supported in part by Grant-in-Aids for Scientific Research (No. 22580379 to K.K. and No. 23580282 to O.A.) from the Ministry of Education, Science and Culture, Japan.

\section{Conflict of interest}

The authors declare that there are no conflicts of interest. 


\section{References}

Bates, S.S., 1998. Ecophysiology and metabolism of ASP toxin production. In: Anderson D.M. et al. (Eds.), Physiological Ecology of Harmful Algal Blooms. Springer-Verlag, Berlin Heidelberg, Germany, pp. 405-426.

Bates, S.S., Bird, C.J., De Freitas, A.S.W., Foxall, R.A., Gilgan, M., Hanic, L.A., Johnson, G.R., Mc Culloch, A.W., Odense, P., Pocklington, R., Quilliam, M.A., Sim, P.G., Smith, J.C., Subba Rao, D.V., Todd, E.C.D., Walter, J.A., Wright, J.L.C., 1989. Pennate diatom Nitschia pungens as the primary source of domoic acid, a toxin in shellfish from eastern P.E.I. Can. J. Aquat. Sci. 46, 1203-1215.

Brand, L.E., Sunda, W.G., Guillard, R.R.L., 1983. Limitation of marine phytoplankton reproductive rates by zinc, manganese, and iron. Limnol. Oceanogr. 28, 1182-1198.

Daigo, K., 1959. Studies on the constituents of Chondria armata, II. Isolation of an anthelmintical constituent. J. Jpn. Pharm. Assoc. 79, 353-356.

Debonnel, G., Beauchesne, L., De Montigny, C., 1989. Domoic acid, the alleged 'mussel toxin', might produce its neurotoxic effect through kainate receptor activation: an electrophysiological study in the rat dorsal hippocampus. Can. J. Physiol. Pharmac. 67, 29-33.

Fox, T.C., Guerinot, M.L., 1998. Molecular biology of cation transport in plants. Annu. Rev. Plant Mol. Biol. 49, 96-669.

Guillard, R.R., Ryther, J.H. 1962. Studies of marine planktonic diatoms. I. Cyclotella nana Hustedt, and Detonula confervaceae (Cleve) Gran. Can. J. Microbiol. 8, 229-239.

Japan Food Hygien Association, 2005. Domoic acid. In: Shokuhin Eisei Kensa Shishin (Manual for Methods for Food Sanitation Testing). Environmental Health Bureau, 
Ministry of Health and Welfare, Tokyo, Japan, pp. 660-673.

Kotaki, Y., Koike, K., Sato, S., Ogata, T., Fukuyo, Y., Kodama, M., 1999. Confirmation of domoic acid production of Pseudo-nitzschia multiseries isolated from Ofunato Bay, Japan. Toxicon 37, 677-682.

Kuwano, K., Matsuka, S., Kono, S., Ninomiya, M., Onishi J., Saga N., 1998. Growth and the content of laurinterol and debromolaurinterol in Laurencia okamurae (Ceramiales, Rhodophyta). J. App. Phycol. 10, 9-14.

Martin, J.H., Gordon, R.M., Fitzwater, S.E., 1991. The case for iron. Limnol. Oceanogr. 36, 1793-1802.

Martin, J.H., Coale, K.H., Johnson, S., Fitzwater, S.E., Gordon, R.M., Tanner, J., Hunter, C.N., Elrod, V.A., Nowicki, J.L., Coley, T.L., Barber, R.T., Lindley, S., Watson, J., Van Scoy, K., Law, C.S., Liddicoat, M.I., Ling, R., Stanton, T., Stockel, J., Collins, C., Anderson, A., Bidigare, R., Ondrusek, M., Latasa, M., Millero, F.J., Lee, K., Yao, W., Zhang, Z., Friederich, G., Sakamoto, C., Chavez, F., Buck K., Kolber, Z., Greene, R., Falkowski, P., Chisholm, W., Hoge, F., Swift, R., Yungel, J., Turner, S., Nightingale, P., Hatton, A., Liss, P., Tindale, N.W., 1994. Testing the iron hypothesis in ecosystems of the equatorial Pacific Ocean. Nature 371, 123-129.

Mukhopadhyay, M.J., Sharma, A., 1991. Manganese in cell metabolism of higher plants. The Bot. Rev. 57, 117-149.

Noguchi, T., Arakawa, O., 1996. Distribution of domoic acid in seaweeds occurring in Kagoshima, southern Japan. Natural Toxins 2, 521-526.

Perl, T.M., Bedard, L., Kosatsky, T., Hockin, J.C., Todd, E.C., Remis, R.S., 1990. An outbreak of toxic encephalopathy caused by eating mussels contaminated with domoic acid. The 
Provasoli, L., 1963. Growing marine seaweeds. In: De Virville, D., Feldmann, J. (Eds.) Proceedings of the Fourth International Seaweed Symposium. Pergamon Press, Oxford, UK, pp. 9-17.

Provasoli, L., 1968. Media and prospects for the cultivation of marine algae. In: Watanabe, A., Hattori, A. (Eds.) Cultures and Collections of Algae, Proc. U.S.-Japan Conf., Hakone, 1966. J. Soc. Plant Physiol., Tokyo, Japan pp. 63-75.

Ramsey, U.P., Douglas, D.J., Walter, J.A., Wright, J.L.C., 1998. Biosynthesis of domoic acid by the diatom Pseudo-nitzschia multiseries. Natural Toxins 6, 137-146.

Strain, S.M., Taker, R.A.R., 1991. Hippocampal damage produced by systemic injections of domoic acid in mice. Neurosci. 44, 343-352.

Sunda, W.G., Huntsman, S.A., 1995. Iron uptake and growth limitation in oceanic and coastal phytoplankton. Marine Chem. 50, 189-206.

Teitelbaum, J.S., Zatorre, R.J., Carpenter, S., Gendron, D., Evans, A.C., Gjedde, A., Cashman, N.R., 1990. Neurologic sequelae of domoic acid intoxication due to the ingestion of contaminated mussels. New Eng. J. Medi. 322, 1781-1787.

Thomas, J.S., Smith, G. J., Amy, T.C., Portia, N.S., 2012. Condensation of the isoprenoid and amino precursors in the biosynthesis of domoic acid. Toxicon 59, 25-33.

Wright, J.L.C., Boyd, R.K., De Freitas, A.S.W., Falk, M., Foxall, R.A., Jamieson, W.D., Laycock, M.V., Walter, J.A., 1989. Identification of domoic acid, a neuroexcitatory amino acid, in toxic mussels from eastern P.E.I. Can. J. Chem. 67, 481-490.

Wright, J.L.C., Falkl, M., McInnes, A.G., Walter, J.A., 1990. Identification of isodomoic acid D and two new geometrical isomers of domoic acid in toxic mussels. Can. J. Chem. 68, 
278 Zaczek, R., Coyle, J.T., 1982. Excitatory amino acid analogues: neurotoxicity and seizures.

$279 \quad$ Neuropharmacol. 21, 15-26.

280 Zaman, L., Arakawa, O., Shimosu, A., Onoue, Y., Nishio, S., Shida, Y., Noguchi, T., 1997.

281 Two new isomers of domoic acid from a red alga, Chondria armata. Toxicon 35, 205- 
Figure captions

Fig. 1. Explant of C. armata cultured in a 24-well plate for 7 days (upper), or in 1-L flat-bottom flasks for 157 days (lower). Arrows indicate trichomes.

288

Fig. 4. DA content of explants cultured with media containing different concentrations of nutrients (see the legend of Fig. 2), and of wild C. armata specimens. Data are shown as the value of pooled explants for each medium (grey columns), and mean (black

Fig. 2. Growth rate of explants cultured with media containing different concentrations of nutrients. N·P·Fe (A) was prepared with autoclaved seawater, and the other media with filter-strilized seawater. Relative concentration of nutrients in $\mathrm{N} \cdot \mathrm{P} \cdot \mathrm{Fe}(\mathrm{A})$, $\mathrm{N} \cdot \mathrm{P} \cdot \mathrm{Fe}, 1 / 2 \mathrm{~N} \cdot \mathrm{P} \cdot \mathrm{Fe}$, and $1 / 4 \mathrm{~N} \cdot \mathrm{P} \cdot \mathrm{Fe}$ were $100,100,50$, and $25 \%$, respectively. Data are shown as individual values (open circles) and the mean of each medium (bars).

Fig. 3. Selected ion chromatograms (m/z 312) of a C. armata explant extract (upper) and the DA standard (lower). column) and SD (error bar) of three wild lots. 

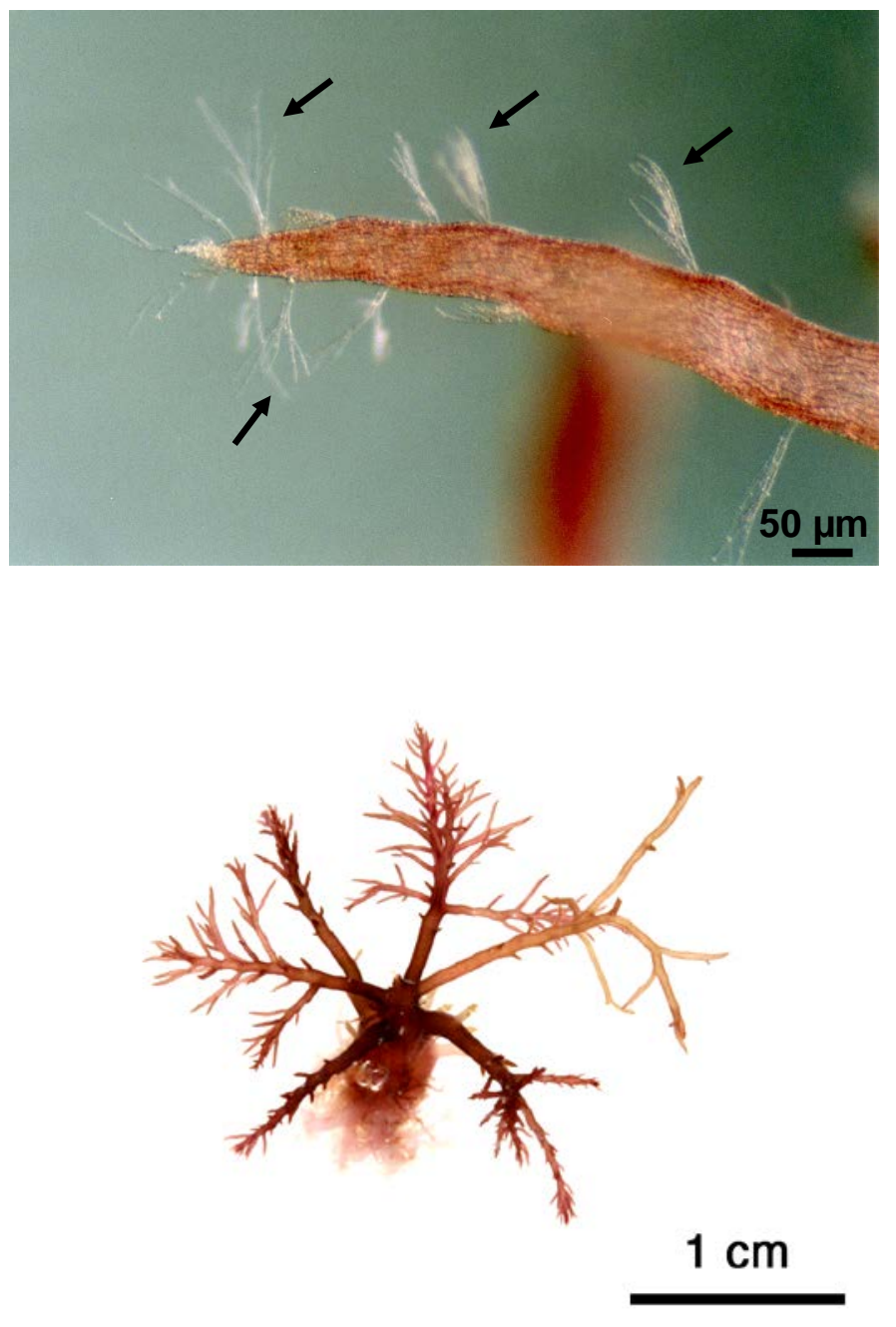

Fig. 1 


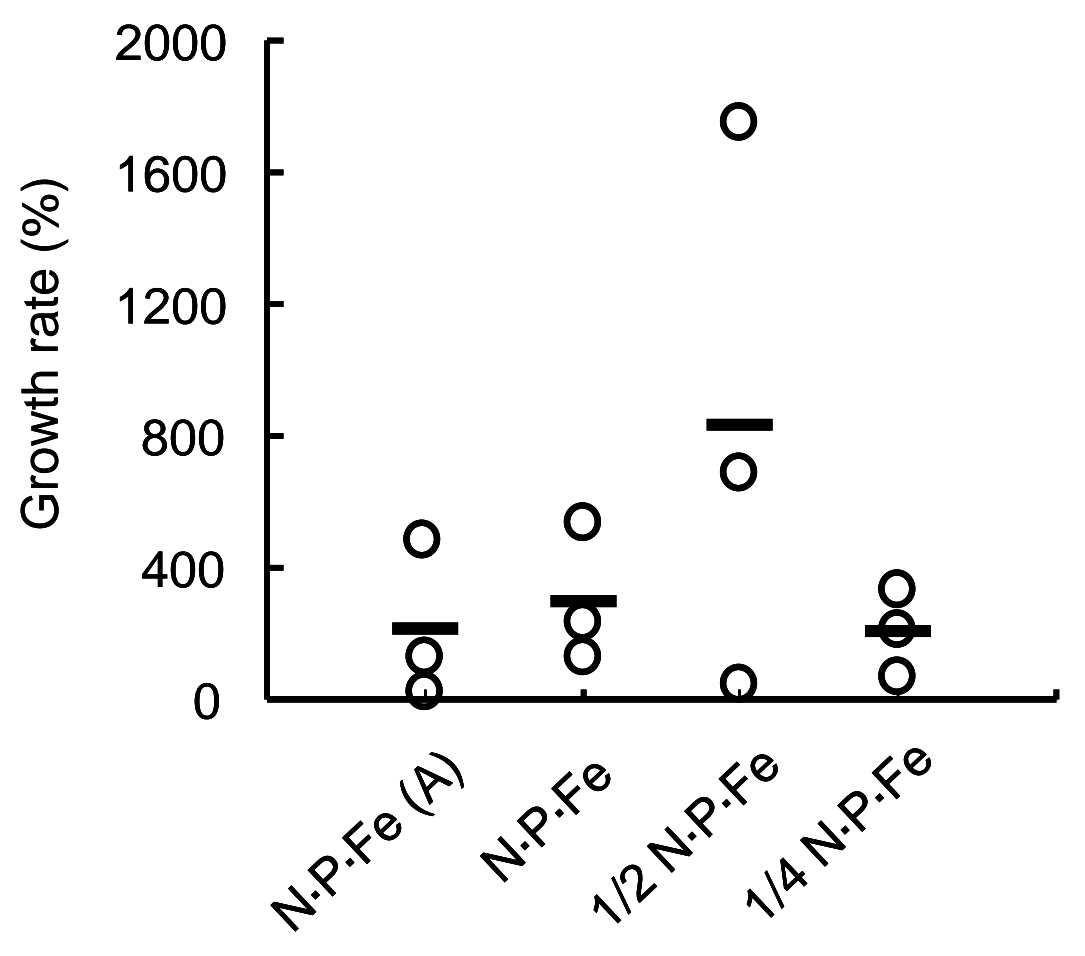

Fig. 2 


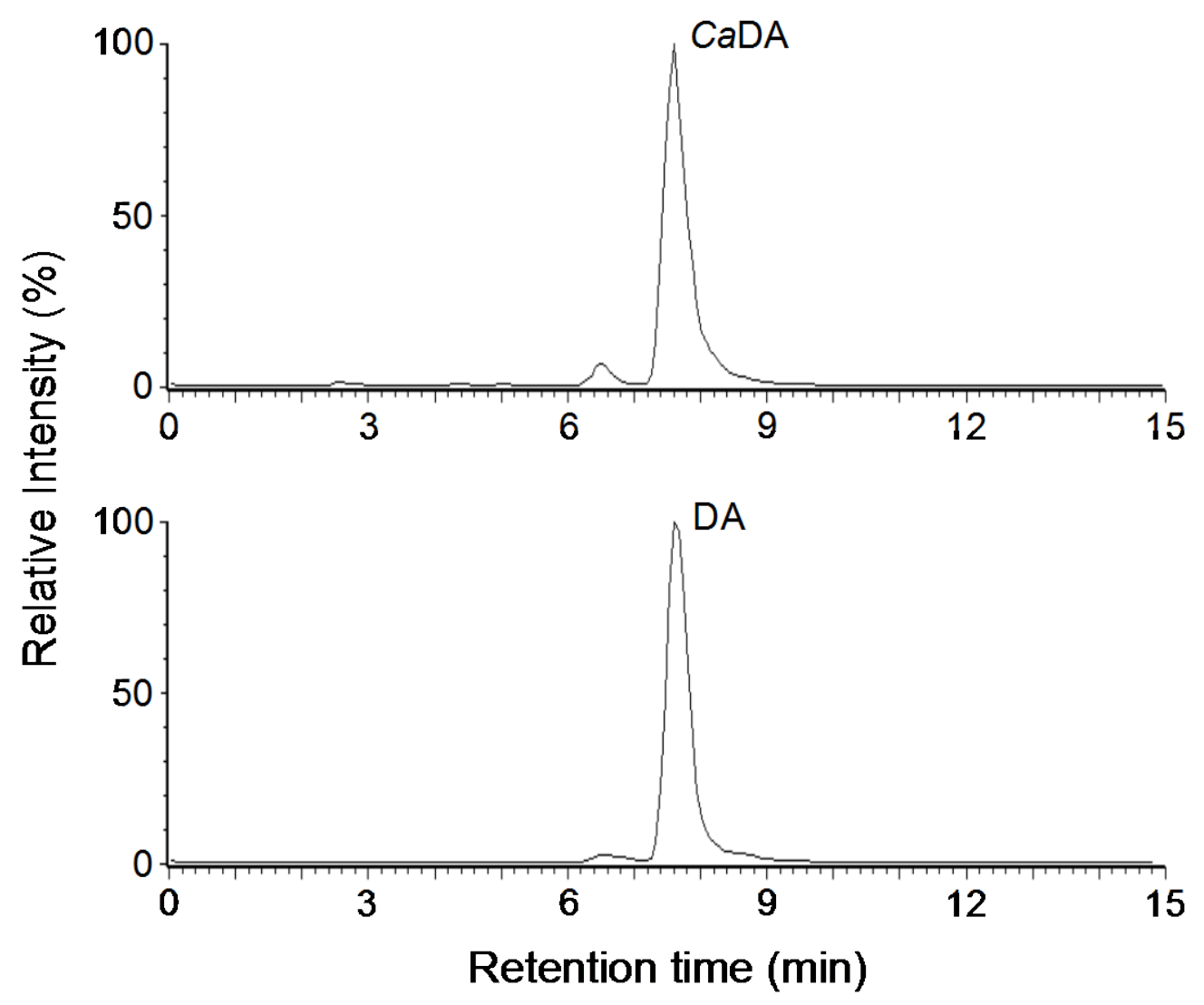

Fig. 3 


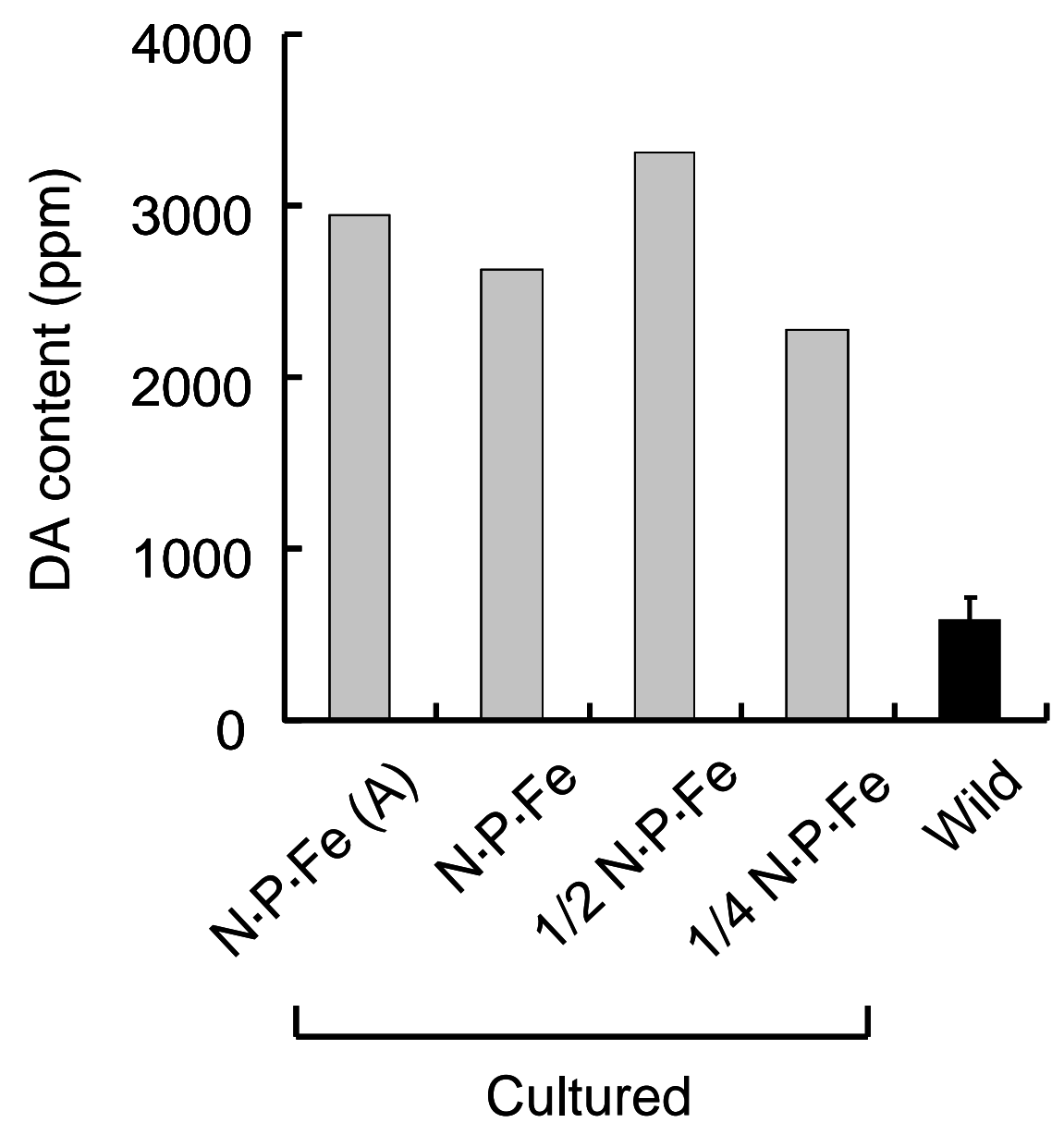

Fig. 4 
Table 1. Nutrient composition of mPES and N·P·Fe

\begin{tabular}{lllc}
\hline Medium & Nutrient & Component & Concentration $(\mu \mathrm{M})^{*}$ \\
\hline \multirow{2}{*}{ mPES } & $\mathrm{NaNO}_{3}$ & & 807 \\
& $\mathrm{Na}_{2}$ glycerophosphate & & 45.4 \\
& Fe-EDTA $3 \mathrm{H}_{2} \mathrm{O}$ & & 8.78 \\
\cline { 2 - 4 } & Trace metals & $\mathrm{Na}_{2} \mathrm{EDTA} \cdot 2 \mathrm{H}_{2} \mathrm{O}$ & 13.4 \\
& & $\mathrm{FeCl}_{3} \cdot 6 \mathrm{H}_{2} \mathrm{O}\left(\mathrm{Fe}^{3+}\right)$ & 0.878 \\
& & $\mathrm{H}_{3} \mathrm{BO}_{3}\left(\mathrm{BO}_{3}{ }^{3-}\right)$ & 90.7 \\
& & $\mathrm{MnCl}_{2} \cdot 2 \mathrm{H}_{2} \mathrm{O}\left(\mathrm{Mn}^{2+}\right)$ & 3.57 \\
& & $\mathrm{ZnCl}_{2}\left(\mathrm{Zn}^{2+}\right)$ & 0.375 \\
& & $\mathrm{CoCl}_{2} \cdot 6 \mathrm{H}_{2} \mathrm{O}\left(\mathrm{Co}^{2+}\right)$ & 0.083 \\
\cline { 2 - 4 } & Vitamins & $\mathrm{Vitamin}_{12}$ & 0.001 \\
& & $\mathrm{Vitamin}_{1}$ hydrochloride & 0.291 \\
& & $\mathrm{Vitamin}^{\mathrm{H}}$ & 0.004 \\
\cline { 2 - 4 } & $\mathrm{HEPES}$ & & 823 \\
\hline $\mathrm{N} \cdot \mathrm{P} \cdot \mathrm{Fe}$ & $\mathrm{NaNO}$ & & 807 \\
& $\mathrm{Na} 2 \mathrm{glycerophosphate}$ & & 45.4 \\
& Fe-EDTA $3 \mathrm{H}_{2} \mathrm{O}$ & & 8.78 \\
\hline
\end{tabular}

*Media were prepared by adding $2 \mathrm{ml}$ of nutritive salt solution to $100 \mathrm{ml}$ of sterilized natural seawater, and the numerical values here indicate the final concentration. EDTA = ethylenediaminetetraacetic acid, HEPES = 2-[4-(2-hydroxyethyl)-1-piperazinyl]-ethanesulfonic acid. 
Table 2. ${ }^{1} \mathrm{H}-\mathrm{NMR}$ data of CaDA in comparison with DA (Wright et al., 1990)

\begin{tabular}{lll}
\hline Position & DA & CaDA \\
\hline 2 & $3.98 \mathrm{~d}$ & $3.94 \mathrm{~d}$ \\
3 & $3.05 \mathrm{dddd}$ & $3.02 \mathrm{~m}$ \\
4 & $3.84 \mathrm{ddd}$ & $3.81 \mathrm{~m}$ \\
5 & $3.49 \mathrm{dd}$ & $3.48 \mathrm{dd}$ \\
& $3.71 \mathrm{dd}$ & $3.68 \mathrm{dd}$ \\
6 & $2.50 \mathrm{dd}$ & $2.45 \mathrm{dd}$ \\
& $2.76 \mathrm{dd}$ & $2.70 \mathrm{dd}$ \\
$2^{\prime}$ & $6.13 \mathrm{~d}$ & $6.11 \mathrm{~d}$ \\
$3^{\prime}$ & $6.35 \mathrm{dd}$ & $6.32 \mathrm{dd}$ \\
$4^{\prime}$ & $5.78 \mathrm{dd}$ & $5.76 \mathrm{dd}$ \\
$5^{\prime}$ & $3.30 \mathrm{dq}$ & $3.23 \mathrm{~m}$ \\
$1^{\prime}-\mathrm{Me}$ & $1.81 \mathrm{~s}$ & $1.78 \mathrm{~s}$ \\
$5^{\prime}-\mathrm{Me}$ & $1.27 \mathrm{~d}$ & $1.23 \mathrm{~d}$ \\
\hline
\end{tabular}

Chemical shifts are expressed in ppm (internal standard, $\mathrm{CH}_{3} \mathrm{COOD}=2.06 \mathrm{ppm}$ ). Letters following the chemical shifts indicate the configuration of signals as follows; $\mathrm{s}=$ singlet, $\mathrm{d}=$ doublet, $\mathrm{q}=$ quartet, $\mathrm{m}=$ multiplet. 